\title{
ТЕОРЕТИЧЕСКИЕ ОСНОВЫ ОЦЕНКИ ЭФФЕКТИВНОСТИ ФУНКЦИОНИРОВАНИЯ ГОСУДАРСТВЕННОГО СЕКТОРА
}

\author{
(c) 2019 Ревкуц Александра Валерьевна \\ соискатель \\ Сибирский федеральный университет, Россия, Красноярск \\ E-mail:sebtk@mail.ru \\ (c) 2019 Демченко Светлана Капитоновна \\ профессор \\ Сибирский федеральный университет, Россия, Красноярск \\ E-mail: demchenko.svet@mail.ru \\ (c) 2019 Подопригора Владимир Георгиевич \\ профессор \\ Сибирский федеральный университет, Россия, Красноярск \\ E-mail: vpodoprigora@sfu-kras.ru
}

(C) 2019 Горев Владимир Петрович

профессор

Россия, Красноярск

E-mail: gorev_vladimir@mail.ru

В статье рассмотрены теоретические основы эффективности государственного сектора. Предложена классификация теоретических подходов к оценке эффективности его функционирования. Сделан вывод, что при исследовании эффективности функционирования государственного сектора требуется расширенная трактовка эффективности и предлагается определение «макроэкономической эффективности функционирования государственного сектора»

Ключевые слова: государственный сектор, национальная экономика, макроэкономическая эффективность функционирования госсектора, воспроизводственный подход

Государственный сектор является неотъемлемым элементом национальной экономики любой страны и под влиянием различных факторов (экономических, социальных, политических, институциональных) подвержен постоянным трансформационным изменениям. Двадцать первый век характеризуется качественной трансформацией базовых принципов функционирования как национальных экономик промышленно развитых стран мира, так и мирового хозяйства в целом. В частности, структурные проблемы развития экономики в различных странах мира, в том числе в России, обуславливают потребность в формировании новой системы, которая позволила бы обеспечить экономическую стабильность государства и социальную защищенность граждан. Фундаментальные исследования национальной экономики и полученные результаты являются ключевой основой для формирования экономической политики государства и обеспечения экономиче- ского роста.

В исследованиях национальной экономики важным является изучение структурных особенностей и отдельных структурных элементов, которые во многом определяют эффективность функционирования экономической системы страны, ее способность к прогрессивному развитию, интернационализации и обеспечению потребностей населения. Трансформацию государственного сектора можно назвать одним из наиболее значимых институциональных преобразований российской экономики, в результате которого была устранена монополия государства на средства производства и сформирован негосударственный сектор экономики.

Несмотря на довольно длительный период времени (около тридцати лет) после перехода от командно-административной модели к рыночной, в российской экономике остаются проблемы, связанные с сырьевой ориентацией, диспропорциями в отраслевой и региональной 
структурах, увеличением дифференциации доходов и низкими темпами роста уровня и качества жизни населения. Решение данных проблем вызывает необходимость исследования влияния процессов трансформации государственного сектора (изменения масштабов, экономического содержания и функциональной роли, сфер и направлений деятельности государственного сектора), связанных с преобразованием экономических отношений, на эффективность его функционирования. Необходимо отметить, что к определению понятия государственного сектора есть два основных подхода. В узком смысле под государственным сектором авторы понимают часть национальной экономики, совокупность хозяйствующих субъектов [2].

В данном диссертационном исследовании мы основываемся на трактовке государственного сектора в широком смысле как совокупности хозяйствующих субъектов, хозяйственных объектов и экономических отношений, подразумевающих применение со стороны государства как прямых (административно-хозяйственных), так и косвенных (макроэкономических) методов регулирования экономики [2], что позволяет расширить трактовку процесса трансформации государственного сектора, рассматривая при этом не только изменение его масштабов, но и другие аспекты, связанные с преобразованием экономических отношений.

Проблемам преобразования экономических отношений и влияния данных процессов на динамику национальной экономики, изучению экономического содержания и функциональной роли государственного сектора в рыночной экономике посвящены труды меркантилистов У. Стаффорда, Т. Мана, А. Монкретьена, А. Серра и др.; основоположников классической политэкономии У. Петти, П. Буагильбера, Ф. Кенэ, А. Тюрго, В. Мирабо, В. Дюпона де Немура, Г. Летрона, А. Смита, Д. Рикардо, Дж.С. Милля, К. Маркса, Ф. Энгельса; представителей неоклассического направления У. Джевонса, Л. Вальраса, К. Менгера, Ф. Визера, Э. Бем-Баверка, А. Маршалла, Дж.Б. Кларка, А. Пигу, Дж. Хикса; создателей кейнсианского, неокейнсианского и посткейнсианского направлений Дж.М. Кейнса, Дж. Хикса, Э. Хансена, Р. Харрода, Дж. Робинсон, П. Страффа.

Институциональные основы трансформации государственного сектора, проблемы влияния институциональных изменений на качество и эффективность производства государственных услуг раскрыты в работах А. Аузана, А. Берли, А. Вагнера, Т. Веблена, Дж. Гэлбрейта, Т.В. Игнатовой, Е.А. Капогузова, Дж.-М. Кларка, Дж. Коммонса, Р. Коуза, Г. Минза, У. Митчелла, Д. Норта, Р. М. Нуреева, Д. Родрика, Дж. Уилсона, Р. Финдли.

В российской науке вопросы государственного регулирования воспроизводственных процессов активно исследовали К.А. Белокрылов, С.Ю. Глазьев, Е.Г. Казанцева, М.Е. Коновалова, О.С. Макаренко, В.М. Полтерович, О.С. Сухарев, С.А. Тертышный, Л.Н. Шереметьева и др.

Изучением эффективности функционирования государственного сектора, изменения его масштабов занимались такие исследователи как Э.Б. Аткинсон, Е. В. Балацкий, С. Браун, П. Джексон, Н.А. Екимова, В.А. Исаев, О.А. Кокорина, Дж. Кендалл, Дж. Кендрик, М. Кнап, В.А. Конышев, М.В. Курбатова, Р. Масгрейв, П. Масгрейв, Е.В. Пономаренко, Е.Г. Попкова, Дж.Э. Стиглиц, Д. Черников, В.А. Шабашев, Л. С. Шаховская и др.

Высоко оценивая вклад всех исследователей в развитие указанного направления экономической науки, следует подчеркнуть, что на данный момент вопросы трансформации государственного сектора, его влияния на воспроизводственные процессы, необходимости оценки эффективности функционирования в национальной экономики являются актуальными. Государственный сектор обладает властными рычагами, имеет возможность оказывать воздействие на все фазы воспроизводственного процесса, на весь комплекс социально-экономических отношений.

Систематизация основных подходов к определению эффективности функционирования государственного сектора позволила выделить концепции, в основе которых лежит анализ качества администрирования, образования, здравоохранения и общественной инфраструктуры, что позволяет оценить государственный сектор не только с количественной, но и с качественной стороны (С.Ю. Глазьев, Э.Б. Аткинсон, Дж.Э. Стиглиц).

Также можно выделить концепциюю стандартных социально-экономических индикаторов (general Musgravian indicators), к которым относятся: дистрибутивность, стабильность и производительность (Р. Масгрейв, П. Масгрейв).

Подход, основанный на методологии «трех Э» во главу угла определения эффективности госсектора ставит - экономию (economy), эф- 
фективность (efficiency) и производительность (effectiveness) (С.А. Абрамов, В.Н. Островская, Т.Н. Митрахович, И.А. Морозова, А.С. Пугиев, С.Э. Акопов, Е.Г. Попкова, Р.С. Безлюдный, А.Н. Борисов, Д.В. Богданов, С.А. Волконская, С.К. Волков, Ю.И. Дубова, Т.А. Литвинова, Л.И. Кукаева, Л.С. Шаховская и др.). В основе концепции «трех Э»: экономия (economy), эффективность (efficiency) и производительность (effectiveness). Показатель общей социальной эффективности государственных вложений, согласно этому подходу, может рассчитываться по двум формулам, которые позволяют понять, за счет которой факторной группы происходит изменение социальной эффективности.

Целевой подход: идея экономической эффективности использования основных видов ресурсов и достижения генеральной цели развития любого государства - формирования ресурсосберегающей экономики лежит в основе целевого подхода, разработанного Е.В. Балацким, В.А. Конышевым, Дж. Кондриком, Д. Черниковым и др.

Техническая концепция эффективности Дж. Кендалла, М. Кнапа, С. Брауна, П. Джексона основывается на кривой производственных возможностей (production possibility curve). Идея заключается в наилучшем с позиций достигнутых результатов использовании имеющихся ресурсов за счет качественного управления, надлежащей координации работы, выбора технологий, поддержания необходимых стимулов.

Равновесный подход основывается на принципе «золотого сечения» связанным с числами Л. Фибоначчи [11], в соответствии с которым возможно достижение равновесной структуры национальной экономики, обеспечивающей эффективное взаимодействие между государственным и частным секторами. Данная концепция базируется на теории динамических систем и находит эмпирическое подтверждение [4].

Динамический подход основывается на идее изменчивости секторальной структуры национальной экономики. Одной из целей регулирования является определение идеального структурного соотношения масштабов государственного и частного секторов национальной экономики. Для решения данной задачи используют теорию динамических систем, в частности, модели типа «хищник-жертва», посредством которых описывается взаимодействие двух секторов экономики: частного и государственного. Один из секторов фигурирует в качестве хищ- ника, агрессивный сектор захватывает ресурсы другого сектора, а другой выступает в качестве жертвы.

Т. Веблен [7], Дж. Гэлбрейт [8], поднимали проблему оценки роли государства в качестве института рыночной экономики. Институциональный подход рассматривает эффективность деятельности государственного сектора в условиях трансформационной (неравновесной) экономики с позиции институциональных аспектов. В частности О.А. Кокорина отмечает, что институциональная эффективность отражает цели институциональных агентств на микроуровне и мезоуровнях [9]. Е.В. Пономаренко, В.А. Исаев рассматривают вопросы, связанные с институциональными изъянами государства и проблемой эффективности государственного сектора экономики [10].

Р. Финдли и Дж. Уилсон, основываясь на идеях Д. Норта предложили модели, обосновывающие оптимальные размеры госсектора с точки зрения институционального подхода. В данной модели объем производства в национальной экономике зависит от двух факторов: технических возможностей частного сектора и организационных возможностей государственного сектора, занимающегося созданием институциональной среды для частного бизнеса [3].

Анализ подходов к оценке эффективности показал, что адекватную оценку эффективности деятельности государственного сектора на практике дать чрезвычайно трудно, поскольку анализ показателей эффективности осуществляется экономистами по различным группам индикаторов, которые часто мало связаны между собой, поэтому любые попытки это сделать подвергаются серьезной критики сторонников противоположных подходов. Поэтому актуальным вопросом является формирование обобщенной системы критериев оценки эффекта от функционирования государственного сектора в динамике, по которым можно было бы сравнивать различные экономические системы в территориальном, в отраслевом и в историческом аспектах [12].

Е.В. Балацкий и В.А. Конышев поднимали идею учета воспроизводственных аспектов динамики государственного сектора. Авторы отмечали, что диалектическое противоречие, заключенное в государственном секторе, преодолевается не за счет оптимизации его размеров и корректировки в одном направлении, а за счет 
придания системе государственного регулирования большей гибкости и постоянного изменения роли самого государственный сектора[5].

В другой работе авторы выдвигают идею, что при исследовании эффективности функционирования государственного сектора требуется расширенная трактовка эффективности. Речь идет о макроэкономической (общесистемной) эффективности госсектора, которая учитывает насколько эффективно он вписывается в секторальную структуру национальной экономик [4].

Е.В. Балацкий считает, что многоаспектность деятельности государственного сектора порождает подход, в соответствии с которым формируется вектор показателей-индикаторов, косвенно характеризующих его результаты. Затем сформированный вектор частных (индивидуальных) индикаторов сводится к скалярной величине с помощью процедуры усреднения. Получаемая таким образом условная оценка показывает социально-экономический эффект, полученный в результате осуществления соответствующих финансовых вложений [1], например, в национальные программы и проекты.

Основываясь на методологическом подходе Е.В Балацкого и В.А. Конышева к исследованию эффективности госсектора с позиции макроэкономической эффективности, в данной работе предлагается дополнить классификацию подходов к исследованию эффективности госсектора воспроизводственным подходом, который позволяет комплексно оценивать экономическую, социальную, целевую, динамическую эффективность в рамках воспроизводственного подхода как методологического инструментария исследования эффективности функционирования го- сударственного сектора. Дело в том, что эффективность функционирования государственного сектора не всегда можно соизмерить с точки зрения соотношения результата и затрат, особенно в таких сферах как здравоохранение, образование, социальное обеспечение, фундаментальные исследования, экология и др.

Государственный сектор должен осуществлять упорядочивающее, целенаправленное воздействие на социально-экономическую систему страны, и в первую очередь, сосредоточить свои усилия на важнейших сферах производства и распределения.

В свою очередь, оценивать эффективность функционирования государственного сектора целесообразно через индикаторы, отражающие результаты процесса воспроизводства.

Понятие «макроэкономической эффективности функционирования государственного сектора» основано на обобщении теоретических концепций к исследованию категории и отражает необходимость применения воспроизводственного подхода, позволяющего рассматривать эффективность госсектора на макроуровне [13].

Таким образом, «макроэкономическая эффективность функционирования госсектора» определяется эффективностью воспроизводственных процессов национальной экономики, обеспечивающих устойчивое расширенное воспроизводство и экономический рост страны на инновационной основе в сочетании с воспроизводством населения, ростом благосостояния и улучшением окружающей среды. Данная категория включает в себя экономическую, социальную, целевую, динамическую эффективность.

\section{Библиографический список}

1. Балацкий E.В. Проблемы оценки масштабов и эффективности государственного участия в экономике // Вестник Московского университета. Серия 6: Экономика. 1997. № 6. С. 22-44.

2. Балацкий Е.В. Элементы экономики государственного сектора: http://kapital-rus.ru/articles/ (дата обращения: 30.08.2019).

3. Балацкий Е.В., Екимова Н.А. Оценка институционального развития России. М.: Перо, 2016. 263 с.

4. Балацкий Е.В., Конышев В.А. Российская модель государственного сектора экономики. М.: Изд-во «Экономика», 2005. 390 с.

5. Балацкий Е., Конышев В. Воспроизводственные аспекты динамики государственного сектора // Экономист. 2003. № 9. С. 13-20.

6. Балацкий Е.В., Конышев В.А. Российская модель государственного сектора экономики. М.: ЗАО «Издательство «Экономика»», 2005.- 390 с.

7. Блауг М. Веблен, Торстейн Бунде // 100 великих экономистов до Кейнса. СПб.: Экономикус, 2008. С. 66-69.

8. Гэлбрейт Дж. К. Новое индустриальное общество. М.: АСТ, 2004. 608 с. 
9. Кокорина О.А. Эффективность государственного сектора экономики // Вестник Челябинского государственного университета. 2008. № 1. С. 75-83.

10. Пономаренко E.В., Исаев В.А. Экономика и финансы общественного сектора (основы теории эффективного государства): учебник. М.: ИНФРА-М, 2007. 253 с.

11. Стахов А., Слученкова А., Щербаков И. Код да Винчи и ряды Фибоначчи. СПб.: Питер, 2006. 171 с.

12. Факторы устойчивого развития регионов России: монография / А.А. Авцинова, С.Н. Афонин, О.В. Вильчинская, Н.В. Гуремина, С.К. Демченко и др. Новосибирск: ООО «Центр развития научного сотрудничества», 2013. 319 c.

13. Demchenko S.K., Melnikova T.A. The methodology of developing the system of indicators to evaluate the socioeconomic development efficiency // Журнал Сибирского федерального университета. Серия: Гуманитарные науки. 2015. Т. 8. № 11. С. 2356-2384. 